\title{
Restructuring Distance Education in Nigeria Using Information Technology
}

\author{
Bessong, Fidelis Ejar \\ Ubana, Ubana Arikpo \\ Udo, David E
}

Cross River State College Of Education, Akamkpa, Nigeria

Doi:10.5901/ajis.2012.v2n5p43

\section{Abstract}

The closure of University satellite campuses on the $24^{\text {th }}$ August 2001 by the Federal Government Confirms the shabby nature of Distance Education in Nigeria. Distance Education though set up to help solve educational problems, if not properly handled will exacerbate poor quality instruction and contribute to educational problems. Application of computer network services in DE will help enrich the programme and enhance qualitative education. This paper explores the concept and problems of DE in Nigeria and examines the feasibility of the application of Information Technology to it, speculating how the integration of IT may enhance the quality of the learning experience.

\section{Introduction}

Distance education can be defined as an educational process in which a significant proportion of the teaching is conducted by someone removed in space and or time from the learner. (Perraton, \& Tsekoa,(1987). One very common feature of distance education is the difference in geographical location of the teacher (instructor) and the learner. At inception, distance education met hostility from education establishment but today many countries seeking public demands for more schools and more teachers have embraced it. It was given a new status and public recognition by the establishment of open universities, starting in Britain in 1969. This venture has extended to over 25 other countries including Nigeria. These universities offer their own degrees and use a combination of media to teach their students.

Distance education has proved its worthy in areas where traditional schools, colleges and universities have difficulties in meeting demand it has proved useful for three main reasons: they make it possible to reach students who cannot get to a college; the students lend themselves to part time education so that they are not taken out of the work force in order to study. Secondly, they appear to allow economies, in part by avoiding the need for new buildings including housings for students. Thirdly as a result of the above they have been used in rich and poor countries to provide a general education and to improve pedagogical skills, to overcome the barriers of distance and to serve as part of a regular system of continuing education.

In addition to offering education to workers on a part-time basis, it offers opportunities to students in very remote areas who cannot get to a school or a campus where distance education brings in resources from outside, it can help overcome problems of local national isolatyion.

Despite its advantages, distance education presents some particular difficulties, which need to be faced if it is to play a major role in educational development. The first concerns feedback and face to face support for the learner. Learning at a distance can be a cold, dispiriting, lonely and difficult activity, if there is no tutor nearby to help with difficulties in the text, a correspondence course can seem impossibly difficult. Also if there are no other students with whom to share difficulties it can make one narrow sighted (Latchem et al 1999). If there is no mechanism for feedback, then learning can become a one-way process, in which the teacher's or correspondence course's knowledge is all-important and the student's of no account. And, if the 
isolated student has to wait of weeks or even months for a response to written work, then he or she is less likely even to complete the course.

Another problem is about money. Distance education makes economic sense because resources are put into the careful writing, editing and production of teaching materials instead of into the employment of face to - face teachers. Such projects become economically viable only if there are enough students to share the production costs of materials. Where there are few students, they will not justify the cost of production of good courses. The purposes of this paper is to expose the condition of distance education in Nigeria and show it can be restructured using information technology.

\section{Meaning of Distance Education}

Over the years, many educators have defined distance education in varied ways. These definitions have some elements in common which goes to explain the meaning of terminology. Dohmen, (1967) are cited by Keegen 1996 defined it thus; Distance Education is a systematically organized form of self-study in which student counseling, the presentation of learning material and the securing and supervising of students' access is carried out by a team of teachers, each of whom has responsibilities. It is made possible at a distance by means of media, which can cover long distance. The opposite of distance education is direct education or face-to-face education, a type of education that takes place with direct contact between lecturers and students.

Moore, (1973) presented a definition thus: Distance teaching may be defined as the family of instructional methods in which the teaching behaviours are executed apart from the learning behaviours including those that in a contiguous situation would be performed in the learner's presence, so that communication between the teacher and the learner must be facilitated by print, electronic, mechanical or other devices.

Moore, repeated this definition without modification in 1977.

Holmberg, (1977) defined it thus:

The term distance education covers the various forms of study at all evels which are not under the continuous, immediate supervision of tutors present with their students in lecture rooms or on the same premises, but which nevertheless, benefit from the planning, guidance and tuition of a tutorial organization.

Garrison \& Stale, (1987) defined it thus: Distance Education implies that the majority of education communication between (among) teacher and student(s) occurs non-continuously. It must involve two-way communication between (among) teachers and student(s) for the purpose of facilitating and supporting the educational process. It uses technology to mediate the necessary two-way communication.

Moore, again in 1990 says distance education is all arrangements for providing instruction through print or electronic communications media to persons engaged in planned learning in a place or time different from that of the instructor or instructors.

Lane, \& Portway, (1994) as cited by Keegen (1996) defined it thus: The term distance education refers to teaching and learning situation in which the instructor and the learner or learners are geographically separated and therefore, rely on electronic devices and print materials for instructional delivery. Distance Education includes distance teaching - the instructor's role in the process - and distance learning - the student's role in the process.

Perraton, Creed \& Robinson (2002) defined distance education as an educational process in which a significant proportion of the teaching is conducted by someone removed in space and or time form the learner. 
Analysis of these definitions leads to the recognition of certain common elements that depicts the meaning of distance education. The separation of teacher and learner is fundamental to all forms of distance education whether they are print-based, audio/radio-based, video/television-based, or computer-based. This separation differentiates distance education from all forms of conventional face-to-face direct teaching and learning. The structuring of learning material and the linking of these learning materials to effective learning by students through an educational organization differentiates distance education from private study, learning from interesting books or cultural television programs.

Distance education therefore means a systematically organized form of self study in which the student(s) receives instruction from the course booklets, or radio, or television or computer or a combination of these media. The geographical location of both instructor and the students usually differ and there is absence of face-to-face interaction between the instructor and the students.

\section{Distance Education in Nigeria}

The awareness of distance education in Nigeria dates back to the 1930s. In 1933, the first sets of graduates were recorded from the University of London. Since then, the establishment of distance education in Nigeria has been on the increase. The University of Lagos in 1974 made the first concerted and conscious effort to establish DE unit in Nigeria, with the name Correspondent and Open Studies Institute (COSIT). Sir Tony Dodds who came on secondment from the International Extension College in UK headed the maiden experiment. This institution made use of mainly print medium or course texts, audiotapes and radio broadcast through the Federal Radio Corporation of Nigeria (FRCN) for instruction. This innovation died as a result to two pronounced factors; the ceasure of free radio broadcast when FRCN wen commercial in 1978 and the ceasure of Federal funding vai NUC the sponsor of the programme in 1989.

The Nigeria Teacher's Institute (NTI), a single mode institution established in 1976 was another bold step in the area of DE in Nigeria. Furthermore, in 1983, another single mode University called National Open University was established. Though it was closed down, later it merged with the University of Abuja to form the nucleus of the centre for Distance Learning and Continuing Education. Apart from these institutions, almost every university in Nigeria runs some form of distance education in their various satellite campuses all over the Federation.

The main medium for course delivery in these distance education centers in course booklets/handouts, which are planned, produced and distributed by the lecturers. In the Nigeria context, distance education is more like the conventional institutions in that there is face-to-face interaction between the students and their lecturers at the study centers. The only significant differences is that lectures are fixed outside office hours mostly in the evenings and weekends. Also their lecturers are employed on a part-time basis from around the study centers. Most often than not these lecturers have far less qualifications and wealth of experience than those in parent universities to ensure conformity with standards in the parents universities. This probably gave room to a lesser quality of education in these centers.

Though enrolment into distance education in Nigeria is high there's a big question are regards the quality of education that exist there. The satellite campuses were more like revenue generation base for the parent universities than an avenue for providing qualitative education. As a result, the federal government on Wednesday $29^{\text {Th }}$ August, 2001 ordered the closure of University satellite campuses in the country.

\section{Application of Information Technology in Distance Education}

Information technology is the application of science to information related problems. It is currently influencing every facet of the society and education is not left out. The possession and accessibility of information has become matters of personal importance. Thus information technology is influencing every 
field of endeavor. It is a term frequently applied to a broad area of activities and technologies associated with the use of computers in communication; but generally it implies the application of computers to store, retrieve, process and disseminate data, (Raiston et al, 2000).

There is an on going fusion between computer technology and telecommunication and this has transformed the whole world into a "global village". People can now easily get in touch, see or speak to one another and exchange information in multimedia, electronically, from any point on the globe to another. Information technology if applied in distance education will make the programme richer and ensure a higher quality of education. In distance learning, there are two basic needs: distribution of teaching materials and stimulation of learning by means of one way or two-way communication. The development of computer links is beginning to blur the distinction between distribution and teaching. It is possible, through an internet connection, both to distribute materials to learners electronically rather than physically and to teach them, by means of a computer program, or engage in dialogue with them by e-mail or computer conferencing (Perraton, et al 2002).

There are a number of computer network services that can be used in restructuring distance education in Nigeria to ensure uniformity in quality. Among these services are:

- Internet Service: - The various applications of the internet could be seen in the following: E-mail, Facsimile, Electronic Bulletin boards, Databases, File Transfer etc.

- Telephone

- Radio

- Television

- Teleconferences

- Compressed Video conferencing

- Teleprocessing

Internet

This is a network of the networks linked by several layers of protocols. It uses the internet protocol to route digital packets of information across a multiplicity of networks and communication media in an efficient and generally reliable manner. Instructors and students in distance education can browse for information via the internet.

Electronic Mail (E-MAIL)

This is an internet-based electronic substitute for the conventional post office. In other words it is the transfer of a message in electronic form from one computer use to another, usually over a network. A user name and password are required to get into the "mail box". The implication is that instructors could send their lecturers or messages to their students in distance education via e-mail and vice-versa. It demands that every student registers and has e-mail address.

Facsimile (FAX)

Internet users having facsimile (fax) machine can receive or send fax via the internet. It is possible for a fax message to be converted to e-mail if the recipient has not a fax machine or prefers e-mail. It is also possible for non-internet users that have fax machine to receive fax message, via the internet provided the sender requested for this service. This provide a good communication system for both the teacher and the learner.

Electronic Bulletin Boards 
The bulletin board service (BBS) is the electronic equivalent of the ordinary notice board. It is just like public bulletin boards. You can post and read messages, which can be personal or otherwise. The difference is that all the messages are electronic and you need a microcomputer, telephone connection and the electronic bulletin board's telephone number. The board's number connects you to a computer that receives and post messages. This is a good communication link in distance education.

Databases

Databases in which specialized information of educational value are stored can be exchanged between the instructors and learners via the internet. Database on the internet can give educational information on radio or television programs to distance education students.

\section{File Transfer}

Any kind of computer file can be set via the internet from one internet user to another.

Telephone

For the instructors to facilitate the smooth running of the distance education programs they could use telephones connected to the computers. For instance, in cases where the teachers need to inform the students of the changes in the course outline, telephone could be very useful. Already in industrialized world, distance-teaching institutions have set up telephone conferences to link students and have taught them through computer networks (Perraton, 1993). Telephone line and a modem are required to get hooked to the internet

Radio

Teachers of distance education programs could deliver their lectures or make announcement through the radio to reach students in a particular area. This method has the disadvantage of students not asking questions on the subjects taught.

\section{Television}

Like in radio, teachers could teach their lectures and make announcements to reach students in a particular area.

\section{Teleconferencing}

This is an improvement of the conventional one-to-one telephone conversation. In this system, numerous people may be simultaneously connected by means of closed circuit television so that discussion can take place even though they do not meet. There are three types of teleconferencing namely;

- Audio conferences: an audio conference uses standard telephone lines to transmit voices to and from the parties in the conference.

- Compressed videoconference: Compressed Digital Video (CDV) transmits live video and audio simultaneously over special telephone lines called Integrated Services Digital Network (ISDN). In video conferencing you can meet face-to-face with your colleagues, or conduct course and seminars without travelling across the state or country. CDV makes your meetings come live by bringing 
your associates into your meeting room. You can see, hear and converse with others located hundreds or even thousands of miles away,, and with the addition of a graphics camera you can view text and graphics. Text and graphics can be transmitted with a document camera to distance learning students.

In America, recent research on distance learning programs shows that distance learning is made possible through videoconferencing (Peterson, 2001). According to he, the National Aeronautics and Space Administration (NASA) uses information technology to provide students with a connection to the "realworld" not only through the Internet and e-mail but also through "face-to-face" video conferencing discussions.

NASA has also been found to

- Share data and knowledge by answering students questions directly.

- Offer helps to students in designing and completion of projects and develop problem-solving skills.

- Support the transformation of the learning environment through innovative, technology enabled opportunities.

- Provide a bridge to digital learning - an education approach that integrates technology connectivity, content and human resources.

By this videoconferencing medium, the teacher is able to receive feedback from the learner, which helps him to improve content and presentation to the learners.

Computer conferences: In computer conference, the keyboard messages are used, that is, the participants use keyboarding from their distant location. They do not hear or see each other.

\section{Teleprocessing}

Teleprocessing refers to a form of online processing in which users at remote workstations are able to access a central computer to store, retrieve or process data. Institutions organizing the distance education programs can enter a query at a workstation, causing the computer to search its files and send the retrieved information to the institution.

Nigeria being a developing nation her DE can use print to present materials, the mail (physical or electronic) to distribute it, and face-to-face tutorial sessions (as through videoconference) for feedback and dialogue. This way, one can ensure that all the learners get the same learning materials, share the same lecturers and the quality of the program will be same all over the nation.

\section{Envisaged Problems}

Some problems are likely going to militate against the effective use of Information Technology in distance education. These include the following:

- Non-availability of funds: Our tertiary institutions are poorly funded; as a result the acquisition of computer and other telecommunication will not be easy

- Irregular supply of electricity: This has become a persistent problem in Nigeria and thus will affect the effective use of information technology.

- Lack of trained personnel in Information Technology: Experts in computer technology are very few. This will no doubt hinder effective use of information technology in distance education.

- Poor NITEL services: NEPA, NITEL services are not reliable and this will hinder effective use of telephones and e-mail in distance education. GSM lines, which are more reliable, are more expensive to use. 


\section{Suggestions}

The following are some suggestions to help make distance education effective.

- A national body should be set up to man distance education in Nigeria. This body should see to the drawing of the curriculum for the various levels, employment of teachers and provision of admission to interested candidates.

- The teachers in distance education should be sent to computer training. The federal government should sponsor this training.

- Teachers in distance education should design instruction effectively.

- The federal and state governments should acquire and provide computers to all levels of education in Nigeria. At the University level, students must have mastered the computer operations in diverse areas.

- The federal government should bring down the cost of net - work connections in Nigeria.

- The federal government should do all within their powers to ensure regular supply of electricity. The privatization of NEPA, I believe will help solve this problem.

\section{Conclusion}

Distance education with all its benefits is a welcomed venture, in the Nigerian situation, there are a lot of lapses as regards uniformity in the content and mode of instruction leading to quantitative and non-qualitative education. However, application of information technology will help over-come these problems and greatly improve the quality of instruction.

\section{References}

Eastmond, Dan (2000) Realizing the Promise of Distance education in low technology countries in Educational Tech. Research and Development 48(2) pp 100-111

Holmberg, B. (1977) Distance education: A survey and Bibliography. London Kogan page

Keegan, D. (1996) Foundations of Distance Education London Routledge.

Latchem, C. Abdullah, S \& Xingfy, D. (1999) “Open and Dual-mode Universities in East and South East, Asia”. Performance improvement Quarterly 12(2), 96-121.

Moore, M. (1977) On a theory of Independent study, Hagen: Fernuniverstat (ZIFF).

Moore, M. (1990) "Background and Overview of Contemporary American Distance Education in Contemporary Issues". In American Distance Education. New York: Pergamon

Petersen, R. (2001) "Real World" connections through videoconferencing - we're closer than you think! Tech Trends, 44(6), pp 5-11

Petersen, H \& Teskoa, K. (1987) Distance Education in the challenge of scale educational development in the small states of the commonwealth, Edited by Bacchus Kazim \& Brock Colin. London: commonwealth Secretariat Publisher.

Perraton, H. Creed, C. Robinson, B. (2002) Teacher Education Guidelines: Using Open and Distance Learning.UNESCO pp38-48

Raiston et al (2000) Encyclopedia of Computer science, U.K: Nature publishing Group. 
